\section{RELACIONES ESPECIALES DE SUJECIÓN. APROXIMACIÓN HISTÓRICA AL CONCEPTO*}

\author{
Luz Marina Gil García** \\ Universidad Militar Nueva Granada \\ Gloria García Coronado \\ Raúl Hernando Esteban García ${ }^{* * *}$ \\ Universidad Militar Nueva Granada
}

Fecha de recepción: 12 de enero de 2009

Fecha de aceptación: 18 de abril de 2009

\section{Resumen}

Este artículo realiza una aproximación histórica al concepto con el propósito de identificar la oportunidad en que surge como categoría jurídica autónoma en el Derecho Administrativo y culminar en los artículos posteriores con la identificación de su impacto en la protección y efectividad de los derechos fundamentales de los servidores públicos de la Fuerza Pública.

\section{Palabras clave}

Relaciones especiales de sujeción, Administración Pública, Estado de derecho, derecho Admi-

Artículo resultado de la investigación "Relaciones especiales de sujeción", adelantada por Grupo Derecho Público de la Universidad Militar Nueva Granada.

* Abogada. Master en Práctica jurídica de la Universidad de Salamanca España. Postgrados en: Derecho administrativo, Universidad Santo Tomás de Aquino, Bogotá. Alta Gerencia del Estado, Escuela Superior de Administración Pública. Bogotá. Seguridad y Defensa Nacional. Escuela Superior de Guerra. Bogotá. Altos estudios en Derecho Constitucional. Universidad de Salamanca, España. Ha sido Directora Ejecutiva de la Justicia Penal Militar; Coordinadora del Grupo Interinstitucional para la Defensa Internacional del Estado del Ministerio de Relaciones Exteriores, entre Junio de 2005 y septiembre de 2006, asesora jurídica del despacho del Ministro de Defensa (2002-2005), jefe de la Oficina Asesora Jurídica del Ministerio Defensa (1995-2002), asesora Jurídica del despacho del Ministro Defensa Nacional (1994-1995), jefe de la División de Negocios Judiciales del Ministerio de Defensa (1990-1994), y abogada litigante del Ministerio Defensa (1988-1990). Docente Investigadora. Universidad Militar Nueva Granada.

*** Asistentes investigadores, estudiantes de Maestría en Derecho Administrativos, Universidad Militar Nueva Granada. nistrativo, Derecho Disciplinario, principio de legalidad, derechos fundamentales, fueros, competencias, categoría jurídica.

\section{SPECIAL RELATIONSHIPS OF SUBJECTION. HISTORICAL APPROACH TO THE CONCEPT}

\begin{abstract}
This time a historical approach aims at the concept to identify the opportunity that arises as a legal category in the Autonomous Administrative Law Articles and lead to subsequent identification of their impact and effectiveness in the protection of fundamental rights of public servants of the security forces.
\end{abstract}

\section{Keywords}

Hold special relations, public administration, rule of law, administrative law, disciplinary law, the principle of legality, rights, privileges, powers, legal category.

\section{INTRODUCCIÓN}

Tanto la administración pública como el derecho administrativo son fenómenos que encuentran sus formas y contenidos en la dialéctica misma de las instituciones, producidas como consecuencia de la formación y consolidación del Estado; desde esta perspectiva, tanto la administración como su derecho pueden ser entendidos como un producto histórico, formado a partir de las complejas relaciones políticas, sociales y jurídicas que se dieron en los orígenes y en la posterior consolidación y actual caracterización del Estado ${ }^{1}$.

Las relaciones de sujeción especial y general, son unos vínculos estrechos entre una persona y el Estado, y que implicaron, en una época, que el individuo quedara a merced del poder, es decir, prácticamente el individuo no tenía o entregaba todos sus derechos y el Estado po-

SANTOFIMIO, José Orlando. Tratado de Derecho Administrativo. Universidad Externado de Colombia. Bogotá. 2002. Tomo I Pág. 188. 
día hacer con él lo que a bien tuviere en cuanto a su relación laboral ${ }^{2}$. Es un vínculo que aún subsiste con algunos matices y que explica la dependencia acentuada de algunos individuos que ostentan además de su condición de servidores públicos ciertos condicionamientos misionales como los militares, los policías o los docentes; o ciertas calidades como los reclusos, entre otros. ${ }^{3}$ En las relaciones de sujeción especial, uno de los sujetos, es siempre la Administración Pública.

Las relaciones especiales de sujeción, se entienden como un mecanismo que dota a la administración de poderes extraordinarios para ejercer potestades; como toda sujeción supone la eventualidad de soportar los efectos de una potestad de otro sobre el propio ámbito jurídico, pero que una vez la potestad es ejercida surgirán ya otras figuras jurídicas subjetivas, derechos, deberes, obligaciones, distintas de la indicada sujeción ${ }^{4}$.

Se basa en un debilitamiento o menoscabo de los derechos de algunos ciudadanos, que fungen como agentes de la Administración del Estado, o de los sistemas institucionalmente previstos para su garantía; lo anterior, como consecuencia de una vinculación cualificada con los poderes públicos emanada de un mandato constitucional, pero especialmente como condición y exigencia del funcionamiento normal del servicio inherente a la Administración Pública.

Es una categorización jurídica específica y propia del Derecho Administrativo; como rama del Derecho de naturaleza estatutaria regula las relaciones singulares y especiales de los sujetos

PAVAJEAU GÓMEZ, Carlos Arturo. Dogmática del Derecho Disciplinario. Universidad Externado de Colombia. Bogotá. 2002, pág. 132

3 MOLANO LÓPEZ, Mario Roberto. Las Relaciones de Sujeción Especial en el Estado Social. Instituto de Estudios del Ministerio Público, Bogotá, 2005.

4 GARCÍA DE ENTERRIA, Eduardo. Curso de Derecho Administrativo, Edit Civitas, Madrid. Reimpresión 2001. Tomo II, pág. 23. que conforman la organización conocida como Administración Pública; en virtud y para efectos de estas relaciones estos sujetos se sustraen del derecho común ${ }^{5}$.

Esta vinculación, puede ser voluntaria, como es el caso de los servidores que en razón de su vinculación con los poderes públicos adquieren una serie de obligaciones que limitan algunos de sus derechos fundamentales; en este evento, esta limitación puede venir acompañada del reconocimiento de algunas prerrogativas o fueros especiales a favor del ciudadano vinculado a esta situación, que afectan principalmente el principio de legalidad, los derechos fundamentales y la protección judicial. ${ }^{6}$

Algunos sectores de la doctrina consideran que en este caso, la restricción de algunos derechos es compensado con otros derechos que adquieren en virtud de la relación especial con los poderes públicos, es decir, como sucede con los militares.

Otros sectores se apartan de esta posición y señalan que, la utilidad de esta categoría estriba en que una vez determinada una relación con la administración y calificada justificadamente como de "especial sujeción", se determina cuál es su finalidad concreta, así como los derechos fundamentales que pueden tener una modulación especial, y con qué intensidad, de acuerdo con su propia peculiaridad y la necesidad de orden que conllevan. ${ }^{7}$

Esta relación de especial sujeción puede incluir: la prohibición absoluta o parcial del ejercicio de un derecho recortando su contenido; la prohi-

5 GARCÍA DE ENTERRIA, Eduardo. Curso de Derecho Administrativo, Edit Civitas, Madrid. Reimpresión 2001. Tomo I, pág. 42.

6 LASAGABASTER HERRARTE, Iñaki. Las Relaciones de Sujeción Especial, Edit Civitas, Madrid 1994, pág 25.

7 BRAGE CAMAZANO, Joaquín. Los límites a los derechos fundamentales, Madrid, Dykinson, 2004, pág. 429. 
bición relativa o con reserva impuesta por la Administración; prohibiciones que pueden ser transitorias o permanentes; la permisión del ejercicio de ciertos derechos y atribuciones con reservas prohibitorias o permisivas, transitorias o permanentes, graduales o totales; la autorización para el ejercicio de ciertas actuaciones y potestades. Algunas son de tipo preventivo y otras, represivo. La relación de sujeción especial, se extiende a la imposición de prestaciones forzosas de carácter personal, que incluyen deberes y obligaciones de hacer y no hacer. Este ámbito define el alcance de las competencias, los fueros y las faltas en vinculaciones concretas con la Administración ${ }^{8}$.

Sin embargo, y de acuerdo con el principio de legalidad inherente a los Estados de Derecho, las relaciones de especial sujeción requieren de respaldo normativo previo a su imposición, generalmente de índole superior; es decir, son materia de reserva legal y excepcionalmente discrecionales. Por lo tanto su incidencia en la libertad del administrado-servidor está condicionada al sistema de libertades implantadas en la Constitución.

La de sujeción, es una situación jurídica pasiva, en relación con el poder de la Administración. Supone la eventualidad de soportar los efectos de esa potestad; pero una vez ejercida la potestad surgen figuras como los deberes, las obligaciones, los derechos, que afectan igualmente la situación jurídica del individuo. "Es una situación puente a las demás"

Ahora bien, el régimen de libertades e imposiciones, en tratándose de ciudadanos comunes y corrientes, se interpreta con fundamento en el principio in dubio pro libertate, es decir la libertad es la regla; en tanto que frente a los servidores

8 GARCÍA DE ENTERRIA, Eduardo. Curso de Derecho Administrativo, Edit Civitas, Madrid. Reimpresión 2001. Tomo II, pág. 107.

9 GARCÍA DE ENTERRIA, Eduardo. Curso de Derecho Administrativo, Edit Civitas, Madrid. Reimpresión 2001. Tomo II, pág. 33. públicos, la limitación es regla de excepción, sin olvidar que como tal debe interpretarse con restricción y congruencia y siempre en beneficio de la libertad individual ${ }^{10}$. En todo caso, la limitación a priori de libertades exige una valoración razonable de cada relación de sujeción especial, en consideración y proporción al fin y naturaleza de la misma.

En su nacimiento, la categoría jurídica de "las relaciones especiales de sujeción", se relacionaba solo con los servidores o funcionarios públicos. A pesar de los múltiples detractores de la categoría, el alcance de esta tiende a ampliarse, en tanto hoy resulta aplicable no solo a los servidores públicos sino también a los particulares que asumen funciones públicas de manera transitoria, por cualquiera de los medios legales para el efecto o permanente como los servicios públicos. Pero la categoría también es una expresión de las competencias intervencionistas del Estado en el ejercicio de algunas profesiones liberales (abogacía, medicina contaduría, entre otras) o actividades reguladas como la educación, la economía, la banca, la moneda etc., o del cumplimiento de funciones de custodia y protección como sucede con las personas privadas de la libertad o que cumplen con su deber de prestación del servicio militar obligatorio.

En Colombia, la Corte Constitucional, ha utilizado la categoría solo en el marco del derecho disciplinario; para explicar la razón de su existencia y finalidad, así como el marco de los deberes y obligaciones cuyo incumplimiento justifica el ejercicio de la acción disciplinaria ${ }^{11}$

Sin embargo, "... resulta claro que la categoría dogmática de la "relación especial de sujeción" tiene aptitud para explicar otras especies del derecho sancionador administrativo, incluso, podríamos afirmar que se abren posibilidades plenamente coherentes de explica-

${ }^{10}$ GARCÍA DE ENTERRIA, Eduardo. Curso de Derecho Administrativo, Edit Civitas, Madrid. Reimpresión 2001. Tomo II, pág. 114

11 Corte Constitucional. Sentencia 417 de 1993: Magistrado ponente Fabio Morón Díaz. 
ción de muy particulares instituciones: 1. La existencia al interior de la "relación especial de sujeción" de grados de exigencia mayor o menor, esto es, de relaciones especiales de sujeción intensificadas y relaciones de sujeción moderadas que explicarían el por qué en algunos ámbitos del servicio público existen regímenes especiales de carácter disciplinario o tratamientos diferenciales en materia de exigencia de deberes ${ }^{12}$ ".

La institución de las Fuerzas Armadas (Militares y de Policía), soporta en su interior una relación especial de sujeción, con grados de intensidad y exigencia mayores a las de los demás funcionarios públicos, originada en la misión constitucional a ellas confiada, que implica la restricción en el ejercicio de ciertos derechos fundamentales; sin embargo, cualquier limitación estará sujeta a los requerimientos constitucionales de legalidad formal y material, como garantía de seguridad jurídica de la Fuerza Pública. En concordancia con la intensidad de esta sujeción, el Estado de derecho permite la restricción o modulación en el ejercicio de ciertos derechos o libertades, pero nunca su supresión o desconocimiento.

"Por el contrario, en la llamada "relación especial de sujeción moderada" las exigencias son menores, tal como ocurre respecto de los particulares que ejercen funciones públicas y de algunos regímenes disciplinarios propios de ámbitos donde operan criterios técnicos o académicos para la selección del personal, inhabilidades, incompatibilidades, etc., como sucede en la autonomía universitaria, entre otros ${ }^{13}$ ".

Las fuentes bibliográficas de esta investigación son realmente escasas; aunque algunos autores nacionales en sus obras sobre Derecho Administrativo hacen una relación tangencial al tema, sólo se encontró en literatura jurídica interna una obra especializada: "La relación especial de

12 PAVAJEAU GÓMEZ, Carlos Arturo, MOLANO LÓPEZ, Mario Roberto. La relación especial de sujeción. Estudios. Universidad Externado de Colombia. 2007, pp. 25 y 26 .

13 GÓMEZ PAVAJEAU, Carlos Arturo, MOLANO LÓPEZ, Mario Roberto. La relación especial de sujeción. Estudios. Universidad Externado de Colombia. 2007, pág. 27. sujeción. Estudios", de los autores Carlos Arturo Gómez Pavajeau y Mario Roberto Molano López, publicada por la Universidad Externado de Colombia, en julio de 2007. Las mayores fuentes se encuentran en la literatura jurídica española; de ahí la necesidad recurrir a la Internet como fuente de información y consulta.

\section{LAS RELACIONES ESPECIALES DE SUJECIÓN, COMO HECHO HISTÓRICO}

Si bien es cierto que las grandes categorías jurídicas del derecho administrativo, surgen y logran su caracterización a partir de la Revolución Francesa, ello no implica que con anterioridad a ella, no se hubieran intentado o perfeccionado ciertas "técnicas" o "relaciones administrativas" 14 , en donde encontremos algunos hechos históricos que puedan constituir antecedentes, de la categoría jurídica que nos ocupa. Aque1los hechos, clases (clérigos, guerreros y siervos) e instituciones, (órdenes monásticas, los feudos, gremios de artesanos u oficios) en donde existen relaciones que constituyen verdaderos vínculos jurídicos entre sus miembros, evidencian desde entonces las características que rigen una relación especial de sujeción ${ }^{15}$.

La ruptura entre la antigüedad y la modernidad se conoce como Edad Media y comprende un lapso de un poco más de diez siglos. Se tiene conocimiento de antecedentes de relaciones especiales de sujeción desde la época conocida como Alta Edad Media, comprendida entre los siglos V y XI D.C., periodo en el que por el llamado compromiso de lealtad que el vasallo le ofrecía al señor feudal por medio de un juramento $^{16}$, se entendía la existencia de una relación de sujeción; en este tipo de dependencia se basaron las relaciones político-económicas

14 SANTOFIMIO, José Orlando. Tratado de Derecho Administrativo. Universidad Externado de Colombia. Bogotá. 2002. Tomo I, pág. 190.

15 HUBERMAN, Leo. Los bienes terrenales del hombre. Editorial Oveja Negra. Abril de 1972.

16 GARCIA MACHO, Ricardo. Las Relaciones de Especial Sujeción en la Constitución Española. Edt. Tecnos, Madrid, 1992. 
de esta época, sin que pueda hablarse de una Administración unitaria ${ }^{17}$ y mucho menos de una función publica ${ }^{18}$.

Estas instituciones de la Edad Media permitieron formar la administración civil y la administración militar a partir de concesiones de las actividades logísticas del reino. Las relaciones de poder giraban alrededor de la propiedad de la tierra y el señor feudal ejercía el poder político con fundamento en el poder territorial.

El monarca concedía los oficios más importantes o las actividades domésticas a los particulares en una relación de vasallaje y fidelidad sin que mediara una relación de carácter jurídico, ni conciencia de lo público. El desarrollo de esta relación de vasallaje creó a la postre las condiciones básicas para afianzar la organización burocrática del Estado Absoluto y la organización militar que luego fueron heredadas por las primeras manifestaciones del Estado Constitucional. ${ }^{19}$

En la "relación de vasallaje" el poder político se encontraba disperso; si bien existían los reinos, el poder de los reyes era simbólico, puesto que éste era detentado por los señores feudales, quienes incluso no estaban sometidos al Rey, de tal manera que no eran sujetos pasivos de sometimiento, sino sujetos que sometían a los siervos de la gleba. Este tipo de sometimiento, basado en lealtades personales, era por si mismo y exclusivamente un poder general de sujeción: El desarrollo de esta relación de vasallaje con el tiempo creó las condiciones básicas para consolidar la organización burocrática del Estado Absoluto y la organización militar que a la postre fueron heredadas

17 PENAGOS, Gustavo. Fundamentos del Derechos Administrativo. Ediciones Librería del Profesional. Primera edición 1993, pág. 16.

18 SANTOFIMIO, José Orlando. Tratado de Derecho Administrativo. Universidad Externado de Colombia. Bogotá. 2002. Tomo I, pág. 196.

19 MOLANO LÓPEZ. Mario Roberto. Las Relaciones de Sujeción Especial en el Estado Social. Instituto de Estudios del Ministerio Público, Bogotá, 2005, pág. 22. por los primeros albores o manifestaciones del estado constitucional", señala Gómez Pavajeau ${ }^{20}$.

Para estos mismos efectos, se pueden destacar las incipientes y rudimentarias organizaciones personales del rey, comunes en toda Europa, ocupadas de los trabajos domésticos; el mayordomo, el jefe del oficio palatino, el jefe de caballerizas reales, el camarero real, el alférez real, que estaba al frente de la guardia real, el notario del real, entre otros ${ }^{21}$.

En ausencia de organización estatal propiamente dicha surge "...un tipo de ejercicio del poder inspirado en relaciones privadas o patrimoniales, como consecuencia, con ausencia total de función administrativa, derecho público o derecho administrativo"22, enseña Santofimio en su multicitada obra.

No obstante, y a pesar de esta discusión, en el medioevo bajo surgen algunas instituciones en las que se encuentran verdaderos antecedentes de las relaciones especiales de sujeción, concretamente en los vínculos jurídicos entre los miembros de las órdenes monásticas y los gremios de oficios (artesanos y comerciantes independientes) con los sujetos encargados de su disciplina, detectándose en ellos los componentes que permiten caracterizar el concepto de este tipo de relaciones, tales como: a) la existencia de un orden jurídico con alcance general y destinatarios universales en un territorio determinado; b) la definición teleológica de un cuerpo normativo especial que contiene una disciplina igualmente especial con destinatarios delimitados dentro del ámbito de regencia del régimen general; c) la sujeción también al régimen general de tales destinatarios específicos;

20 GÓMEZ PAVAJEAU, Carlos Arturo. MOLANO LÓPEZ, Carlos Arturo. La relación especial de sujeción. Estudios. Universidad Externado de Colombia. 2007, pág. 34.

21 SANTOFIMIO, José Orlando. Tratado de Derecho Administrativo. Universidad Externado de Colombia. Bogotá. 2002. Tomo I, pág. 197.

22 SANTOFIMIO, José Orlando. Tratado de Derecho Administrativo. Universidad Externado de Colombia. Bogotá. 2002. Tomo I, pág. 198. 
d) la existencia de autoridades para la aplicación del régimen especial de disciplina. En los gremios hay un maestro y un aprendiz; el primero disciplina y domina ${ }^{23}$.

El absolutismo, concebía en sentido pasivo la posición del individuo frente a la comunidad política, titular de meras cargas, obligaciones y deberes que le imponía un poder público trascendente a todos y cada uno de los individuos y aún al conjunto de todos ellos, como emanado de una u otra forma, de Dios mismo, cuyo vicario en la tierra para el fin de instaurar el orden secular era el Rey. Por eso, los miembros de la comunidad política distintos del Rey, eran calificados de "súbditos", esto es, de "sometidos", en virtud de la previa, general y superior posición trascendental del Príncipe ${ }^{24}$.

En la Edad Moderna que antecedió a la Revolución francesa, y ante el debilitamiento de los feudos y estamentos, se robustece el sector central representado en el Rey y crece de manera inusitada para asumir las nuevas responsabilidades y funciones, ahora públicas y no personales del rey. Para afrontar este reto el Rey se rodea de una serie de servidores, no ya personales sino encargados de las gestiones reales $\mathrm{u}$ "oficio regios "25.

La organización y criterios organizacionales varió en cada uno de los Estados; la institución mas común fue la de los Consejos Reales, cuyas funciones se resumían esencialmente en asesorar al rey, desarrollar asuntos administrativos y administrar justicia. En relación con la organización territorial y local surgieron los lugartenientes, virreyes, gobernadores, capitanes generales, regidores, corregidores, secretarios

23 GÓMEZ PAVAJEAU, Carlos Arturo. MOLANO LÓPEZ, Carlos Arturo. La relación especial de sujeción. Estudios. Universidad Externado de Colombia. 2007, pp. 21 y siguientes.

24 GARCÍA DE ENTERRIA, Eduardo. Curso de Derecho Administrativo, Edit Civitas, Madrid. Reimpresión 2001. Tomo II, pág. 18.

25 SANTOFIMIO, José Orlando. Tratado de Derecho Administrativo. Universidad Externado de Colombia. Bogotá. 2002. Tomo I, pág. 205. de despacho, intendentes, superintendentes, diputados, procuradores, síndicos, entre otros.

En tanto se presume que el rey no actúa injustamente, el derecho regio, gozó de esta misma presunción; de allí nacen categorías jurídicas vigentes durante muchos años, como la presunción de legalidad de los actos administrativos, la ejecutoriedad y ejecutividad de los mismos; pero tan bien surge la doctrina de los oficios públicos con conceptos como sueldo y suspensión del empleo; la potestad disciplinaria; la jerarquía y la competencia, entre otros.

El "derecho regio", es reemplazado por el derecho de policía; es un derecho público diferente del común, a través del cual se pretende atender el cúmulo de responsabilidades asumidas por el naciente Estado moderno del siglo XVIII: salubridad, orden público, educación, respeto, buen orden de la colectividad, régimen de los servidores públicos, entre otras ${ }^{26}$.

La Revolución Francesa, sienta el poder en el asentimiento y control de los individuos que dejan de ser súbditos para convertirse en "ciudadanos". Los individuos, pasan a ser dueños del poder y directos destinatarios de sus beneficios y sujeto activo frente a la Administración ${ }^{27}$.

Este suceso jugó un papel determinante en el surgimiento de la Administración Pública moderna. Los principios de legalidad y de democracia representativa, reforzaron el carácter del funcionario público como agente del Estado e instrumento de la ley. El modelo francés cuenta con una Administración fuertemente centralizada que ejerce funciones de autoridad con un sistema de funcionarios públicos cerrado o de carrera. Sin embargo, el funcionario público no es un trabajador cualquiera, cuyas condiciones

26 SANTOFIMIO, José Orlando. Tratado de Derecho Administrativo. Universidad Externado de Colombia. Bogotá. 2002. Tomo I, pág. 214.

27 GARCÍA DE ENTERRIA, Eduardo. Curso de Derecho Administrativo, Edit Civitas, Madrid. Reimpresión 2001. Tomo II, pág. 18. 
de vinculación son determinadas en forma unilateral por la administración, es decir, es una relación estatutaria, o relación de sujeción especial, según la doctrina alemana.

Las potestades del ejecutivo eran solo las necesarias para ejecutar la ley; siempre dependían de las decisiones de la Asamblea Nacional. Poseía potestad de mando y disciplina; de reglamentación para ejecutar la ley; de ejecutividad para aplicarla a casos concretos a través de actos administrativos. Excepcionalmente podía adoptar actos políticos, que no eran objeto ni de control político ni jurisdiccional. Todo el ordenamiento jurídico estaba cubierto por la ley, "... lo que implica que todos los ciudadanos estaban vinculados a una relación de sujeción general sin derivación de espacios autónomos a favor de la rama ejecutiva ${ }^{28 "}$.

A partir de entonces, la tarea del Estado no consistía en proteger libertades públicas, sino en obrar positivamente en la sociedad para otorgar a los ciudadanos una serie de servicios efectivos que les permitieran mejorar sus condiciones de existencia. De la teoría del Estado gendarme se pasa al Estado-servidor, situación que provocó una nueva manera de relacionarse con los ciudadanos-administrados y con los ciudadanosservidores públicos.

Por lo anterior, debemos colegir que en Francia predominaba un principio de sujeción general de los ciudadanos frente al Estado, basado primordialmente en el principio de igualdad ante la ley.

\section{LAS RELACIONES ESPECIALES DE SUJECIÓN COMO CATEGORÍA JURÍDICA}

El nacimiento teórico y la cuna de la institución, es la doctrina alemana. "Como concepto

28 GÓMEZ PAVAJEAU, Carlos Arturo. MOLANO LÓPEZ, Carlos Arturo. La relación especial de sujeción. Estudios. Universidad Externado de Colombia. 2007, pág. 36. politico especifico, las RES surgen en el ámbito del poder ejecutivo engendrado en la estructura de la monarquía constitucional alemana, como parte de los poderes del monarca, configurando la Administración del Estado como fruto de la autonomía del poder ejecutivo frente al poder legislativo que tuvo mas auge en Alemania que en otras latitudes ${ }^{29 " .}$

Los orígenes de la categorización jurídica de las relaciones especiales de sujeción deben buscarse en las elaboraciones de la doctrina administrativista alemana de fines de siglo XIX y principios del XX. En tal sentido, se ha indicado que uno de los primeros autores que la utilizó fue Paul Laband, en 1901, aplicándola a los funcionarios públicos. Sin embargo, es Otto Mayer quien representa el mayor exponente de la teoría en el derecho público alemán.

El primer autor que utiliza la categoría de relación de sujeción especial aplicada a los funcionarios públicos fue Paul Laband, quien establece una relación funcionario-Estado a través de un contrato que es regulado por el derecho público, donde el Estado para la realización de los fines propios, declara su voluntad de tomar a la persona a su servicio y de otro lado, el funcionario expresa al Estado su deber particular de servicio, de obediencia y fidelidad; el incumplimiento de sus obligaciones es un delito disciplinario.

Ahora bien, uno de los primeros autores que se valió de la categorización que nos ocupa para diferenciar las relaciones de poder, de las relaciones de derecho privado y de las relaciones de derecho de propiedad fue Shmitthenner; esta posición doctrinal sirvió para desemparejar el derecho público del privado, las relaciones públicas de las privadas, pero no sirvió para diferenciar las relaciones de sujeción general con las relaciones de sujeción especial, pues para la época todavía no se había configurado el con-

29 GARCÍA DE ENTERRIA, Eduardo. Curso de Derecho Administrativo, Edit Civitas, Madrid. Reimpresión 2001. Tomo II, pág. 18. 
cepto de relación de sujeción general, y el lugar que ocupaba el ciudadano en sus relaciones con el Estado ${ }^{30}$.

Como ya se indicó, la formación de la teoría se da en el marco de la monarquía constitucional alemana del siglo XIX. La monarquía constitucional alemana, fue en cierta forma una combinación del Estado monárquico con un Estado de Derecho ${ }^{31}$, fundamentado en dos grandes instituciones el Parlamento y el Monarca. Al primero, le competen las relaciones generales con la sociedad que representa (derechos, libertades y garantías), reguladas a través de la ley formal; al segundo, los asuntos domésticos del Estado (organización y administración civil, tributaria y militar), expresados en funciones y atribuciones de subordinación especial, sin regulación legal ni control jurisdiccional ${ }^{32}$. Los poderes del Monarca se confunden con los del ejecutivo.

En todo caso, el primero en dar alcance jurídico a esta categoría fue Paul Laband; y lo hizo con el propósito de aclarar la situación jurídica de los funcionarios públicos en relación con sus superiores. Habló de relaciones contractuales y de poder, que se dan en el servicio público. De estas últimas se deriva la posibilidad de dar órdenes y ejercer coacción. Propone una definición de relación funcionarial en la que incluye por primera vez la noción de "relación especial de poder", que puede ser simple o cualificada, según el grado de voluntariedad que dé base a la relación ${ }^{33}$.

30 GÓMEZ PAVAJEAU, Carlos Arturo. MOLANO López Carlos Arturo. La relación especial de sujeción. Estudios. Universidad Externado de Colombia. 2007, pp. 35 y siguientes.

31 LASAGABASTER HERRARTE. Iñaki. Las relaciones de sujeción especial, Edit Civitas, Madrid 1994, pág. 40.

32 GÓMEZ PAVAJEAU, Carlos Arturo. Dogmática del Derecho Disciplinario. Universidad Externado de Colombia. Segunda Edición, pág. 133.

33 GÓMEZ PAVAJEAU, Carlos Arturo. MOLANO LÓPEZ, Carlos Arturo. La relación especial de sujeción. Estudios. Universidad Externado de Colombia. 2007, pp. 39 y siguientes.
Es así como Otto Mayer y Paul Laband, formulan las ideas esenciales y construyen la formulación teórica del concepto de las relaciones especiales de sujeción a partir de las ideas básicas de "dependencia" y "libertad restringida", asociadas al administrado que ingresa a la órbita de la naciente Administración Pública.

El valor libertad es determinante en la definición de relación especial de sujeción, que hace Mayer, como valor que restringe el poder jerárquico, en tanto es: "... una dependencia acentuada, que se instituye a favor de una determinada administración pública respecto de todos los sujetos que entran en la relación especial prevista". Entablada la relación especial de sujeción, por disposición legal o por el consentimiento del interesado, queda sometido a los poderes que se ejercitan en el seno de la Administración: "... La obligación de servir, según el derecho público, significa una relación de sujeción especial....la obligación de prestar servicios, sea cual fuere su origen, crea un poder jurídico especial que se ejercerá en nombre del Estado o del cuerpo de administración propia sobre el obligado, para mantener y dirigir a éste en el cumplimiento exacto de sus deberes. Este es el poder jerárquico... El poder jerárquico se ejerce de dos maneras distintas: la orden jerárquica y el poder disciplinario... ${ }^{34 "}$.

El autor hace referencia especial a la obligación militar, como "... una obligación que "casi absorbe toda la personalidad del deudor" y que sitúa al soldado o militar en un estado de constante y perpetuo servicio "aun durante la noche y las horas de reposo o cuando tiene permiso, el soldado esta en servicio activo y bajo banderas". Para afianzar esta adecuación de la orden a sus estrictos términos, Otto Mayer concede al subordinado un derecho de examen respecto a la orden emanada por el superior ${ }^{35 "}$.

34 LÓPEZ BENÍTEZ, Mariano. Naturaleza y presupuestos constitucionales de las relaciones especiales de sujeción. Universidad de Córdoba. Civitas. 1994. pp. 56-61.

35 LÓPEZ BENÍTEZ, Mariano. Naturaleza y presupuestos constitucionales de las relaciones especiales de sujeción. Universidad de Córdoba. Civitas. 1994, pp. 65-67. 
E1 concepto fue utilizado por otros autores como Jellinek; pero es Otto Mayer, quien lo impone e introduce como una categoría del Derecho Administrativo ${ }^{36}$, con una regulación eminentemente administrativa que generaba la restricción de los derechos, garantías y libertades básicas sin que hubiese control judicial alguno en relación con las regulaciones o las limitaciones $^{37}$. "... Sujeción significa vínculo de dos personas desiguales desde el punto de vista del Derecho, cuyo contenido lo determina la voluntad de la persona superior. En este sentido, la relación entre el Estado y el súbdito es un vínculo de sujeción importante. Pero principalmente, con esta palabra queremos asignar una relación de sujeción creada especialmente para el súbdito o más bien para una cierta pluralidad de súbditos. Es una relación jurídica de Derecho público por la cual ese individuo está vinculado respecto del Estado, por efecto de la obligación general de regular su conducta conforme a un cierto interés público ${ }^{38 "}$.

Estas tendencias se explican en el marco de la llamada "teoría de la impermeabilidad", "... conforme a la cual todo lo que se produzca al interior de la organización estatal es indiferente a lo jurídico", conforme a la versión clásica del Estado de derecho liberal, vigente para entonces ${ }^{39}$. El Estado

36 LÓPEZ BENÍTEZ, Mariano. Naturaleza y presupuestos constitucionales de las relaciones especiales de sujeción. Universidad de Córdoba. Civitas. 1994, pp. 71-72.

37 GALLEGO ANABITARTE, Alfredo. Las relaciones especiales de sujeción y el principio de la legalidad de la administración. Contribución a la teoría del Estado de derecho. En: "Revista de Administración Pública". ISSN 0034-7639, No. 34-1961, pp. 11-52. Recuperado de: http: //www.cepc.es/rap/Publicaciones/Revistas/1/1961_034_011.PDF, el 08 de junio de 2008.

38 COTINO, Lorenzo. Relaciones de especial sujeción: su diversa evolución en Alemania y España. (particular seguimiento de la jurisprudencia constitucional, contencioso-administrativa y militar de la presente década). En: "Revista del Poder Judicial", (3 $3^{\text {a }}$ Època), no. 55, 1999 (III), pp. 291-324. Recuperado de: http: //www.cotino. net/Publicaciones/

39 LÓPEZ BENÍTEZ, Mariano. Naturaleza y presupuestos constitucionales de las relaciones especiales de sujeción. Universidad de Córdoba. Civitas. 1994, pág. 66, el 08 de junio de 2008. posee una personalidad jurídica y un poder residual, según los cuales, en primer lugar, al interior del Estado no surgen relaciones jurídicas, sino relaciones de autoridad y subordinación en virtud del poder especial del Monarca, que constituyen verdaderas reglas de conducta y deberes de obediencia, sometimiento y restricción de derechos subjetivos, (voluntarias para los funcionarios y obligatorias para los militares y policía, según la naturaleza y fin de la vinculación); en segundo lugar, los asuntos no atribuidos a otro órgano del Estado le correspondían al Ejecutivo, quien poseía un poder organizativo máximo sin limites ni controles ${ }^{40}$.

"Como puede observarse, este proceso histórico que se surte en Alemania se estructura sobre el ejecutivo como titular de potestades administrativas no regidas por el derecho para regular las relaciones internas del Estado, que para ese momento se entendian como aquellas derivadas de los cuerpos de la administración civil, de los servicios que estaban a cargo de la Administración, caso concreto de las prisiones, las escuelas, los hospitales y los distintos servicios públicos que para la época se entendian como exclusivamente administrativos ${ }^{41}$ ".

Por resultar de especial interés para la comprensión de la evolución como categoría jurídica de las relaciones especiales de sujeción, es oportuno detenernos en los elementos de la conceptualización de Otto Mayer, en el marco del positivismo jurídico, como concepto sustantivo, independiente y diferenciado, de la relación general del súbdito, así:

1. Es la manifestación de un vínculo desigual de algunos súbditos con el Estado: Es decir, no todos los vínculos entre el estado y los

40 GÓMEZ PAVAJEAU, Carlos Arturo. MOLANO López Carlos Arturo. La relación especial de sujeción. Estudios. Universidad Externado de Colombia. 2007, pág. 41.

41 GÓMEZ PAVAJEAU, Carlos Arturo. MOLANO LÓPEZ, Carlos Arturo. La relación especial de sujeción. Estudios. Universidad Externado de Colombia. 2007, pág. 45. 
súbditos son relaciones especiales de sujeción; este concepto debe reservarse solo para un tipo concreto de relación "creada especialmente para el súbdito o mas bien para cierta pluralidad de súbditos ${ }^{42}$ ". Mayer, "...entiende que se trata de un vínculo desigual, desde el punto de vista jurídico, esto es, creado jurídicamente de manera especifica para determinados súbditos, con lo cual parte del supuesto de que es una norma de destinación específica, que no se puede aplicar a todos los ciudadanos y que tiene una connotación apriorística ${ }^{43}$ ".

2. Es una dependencia acentuada a favor de la administración, "...que se instituye a favor de una determinada Administración pública respecto a todos los sujetos que entran en la relación especial prevista" ${ }^{44}$, señala Mayer. "...Si la Administración del Estado tiene a su cargo unos intereses específicos, una manera de lograr eficazmente esos objetivos-que son del estado constitucional mismo- es disponiendo de unos medios combinados de manera idónea, en términos de costo-beneficio. Y dado que los servidores del estado son uno de estos medios, la manera de justificar su dependencia como tales medios son los intereses de la eficacia en el cumplimiento de los fines públicos" ${ }^{45}$.

3. Es un estado de libertad y derechos restringidos, en virtud de la vinculación al Estado y solo la necesaria para lograr la eficacia de la Administración. Es una libertad disminuida pero no suspendida en su totalidad:

42 GÓMEZ PAVAJEAU, Carlos Arturo. MOLANO LÓPEZ, Carlos Arturo. La relación especial de sujeción. Estudios. Universidad Externado de Colombia. 2007, pág. 42.

43 LÓPEZ BENÍTEZ, Mariano. Naturaleza y presupuestos constitucionales de las relaciones especiales de sujeción. Universidad de Córdoba. Civitas. 1994, pág. 66.

44 GÓMEZ PAVAJEAU, Carlos Arturo. MOLANO LÓPEZ, Carlos Arturo. La relación especial de sujeción. Estudios. Universidad Externado de Colombia. 2007, pág. 46.

45 LÓPEZ BENÍTEZ, Mariano. Naturaleza y presupuestos constitucionales de las relaciones especiales de sujeción. Universidad de Córdoba. Civitas. 1994, pág. 67. "...vincula la fuente de dicha restricción extraordinaria de derechos con el ingreso material del afectado a la organización administrativa del órgano titular de dicho servicio $46 "$ " "Mayer no propugna un sacrificio pleno de la libertad en aras del funcionamiento de la "gran máquina administrativa"; solo trata de compatibilizar los derechos de los particulares que sirven o se integran a esa máquina con la necesaria e imprescindible eficacia de la misma ${ }^{47}$ ".

4. El fundamento para esa libertad restringida puede ser la ley, como ocurre en el servicio militar (el jurado, el testigo) en donde hay un ingreso obligatorio, "...que la ley habia perfilado hasta sus últimas consecuencias ${ }^{48 "}$. "En el servicio obligatorio este basamento se localiza en la misma ley, supuesta la reserva constitucional que impera para imponer limitaciones a la libertad ${ }^{49}$ ". Desobedecer esa orden (la orden de llamada para entrar en servicio), negarse a entrar en servicio en la época prescrita, acarrea una represión penal; además hace incurrir en daños y perjuicios, es decir, en el pago de las costas ocasionadas por ese hecho ilegal; finalmente cuando se trata del servicio militar se podrá vencer esta resistencia mediante el empleo de la fuerza; se trae al deudor manu militari ${ }^{50}$.

5. El fundamento para esa libertad restringida en el caso de los servidores públicos es

46 GÓMEZ PAVAJEAU, Carlos Arturo. MOLANO LÓPEZ, Carlos Arturo. La relación especial de sujeción. Estudios. Universidad Externado de Colombia. 2007, pág. 46.

47 GÓMEZ PAVAJEAU, Carlos Arturo. MOLANO LÓPEZ Carlos Arturo. La relación especial de sujeción. Estudios. Universidad Externado de Colombia. 2007, pág. 47.

48 LÓPEZ BENÍTEZ, Mariano. Naturaleza y presupuestos constitucionales de las relaciones especiales de sujeción. Universidad de Córdoba. Civitas. 1994, pág. 67.

49 GÓMEZ PAVAJEAU, Carlos Arturo. MOLANO LÓPEZ, Carlos Arturo. La relación especial de sujeción. Estudios. Universidad Externado de Colombia. 2007, pág. 48.

50 LÓPEZ BENÍTEZ, Mariano. Naturaleza y presupuestos constitucionales de las relaciones especiales de sujeción. Universidad de Córdoba. Civitas. 1994, pág. 69. 
una relación profesional semejante a la del acreedor-deudor originada en un contrato; equivalencia que garantiza los poderes de la administración y en especial la exigencia de deberes como el de la obediencia: “... como ocurre con el funcionario...cuando aceptaba su nominación....concluida a través de acto administrativo. ...Cuando se trababa la relación de servicio público propiamente dicho, se trataba de una relación similar a la de deudor-acreedor en la que el deudor era la sometido y el acreedor era la Administración Pública $a^{51}$ ". "Por lo tanto, el poder del superior jerárquico actúa sobre él con sus órdenes y medios disciplinarios. El carácter de ese poder será mas o menos fuerte, según la naturaleza de los servicios que se trata de suministrar ${ }^{52}$ ". El consentimiento del interesado, con la toma de posesión, al acto administrativo, es el fundamento de la restricción y de la asunción de sus deberes: "Por lo tanto, esta relación de servicio, solo podrá crearse con el consentimiento del interesado ${ }^{53 "}$.

6. El poder de mando de la administración, es un poder jurídico, que le permite corregir o disciplinar para el mejoramiento del servicio y si hay lugar sancionar penalmente por el mismo hecho. El poder de mando tiene dos manifestaciones externas, la orden jerárquica y el poder disciplinario.

"Por medio de la orden jerárquica se determina de forma obligatoria la conducta del subordinado y se genera en éste el consiguiente deber de obediencia. La orden puede darse de forma individual o de modo general y puede proceder incluso de autoridades que serían claramente incompetentes para emanar actos

51 LÓPEZ BENÍTEZ, Mariano. Naturaleza y presupuestos constitucionales de las relaciones especiales de sujeción. Universidad de Córdoba. Civitas. 1994, pág.70.

52 GÓMEZ PAVAJEAU, Carlos Arturo. MOLANO LÓPEZ, Carlos Arturo. La relación especial de sujeción. Estudios. Universidad Externado de Colombia. 2007, pág. 48.

53 LÓPEZ BENÍTEZ, Mariano. Naturaleza y presupuestos constitucionales de las relaciones especiales de sujeción. Universidad de Córdoba. Civitas. 1994. pág. 69. administrativos $^{54}$ ". E1 poder disciplinario, es diferente al poder punitivo general del Estado; es de naturaleza correctiva, pedagógica, en interés y mejoramiento del servicio.

7. El poder de mando se extiende no solo al funcionario público, sino también al particular o beneficiario de los servicios o prestaciones, del llamado "establecimiento": "Cualquiera que para obtener ventajas entra en la esfera de actividad de una empresa pública, en una escuela, en un hospital, en la diligencia, en el matadero, etc., renuncia por ello a una parte correspondiente de su libertad personat55. No hay relación jurídica entre el "establecimiento" y el beneficiario, solo una relación de hecho que hace ".... necesario que esa persona haga concordar su conducta con la marcha reglada de la empresa y ello, no en virtud de una obligación contractual que se habría impuesto, sino porque la actividad vital de la empresa que lo rodea es jurídicamente superior. Es preciso que adapte su conducta personal a ella; con el empleo de la fuerza los agentes de la empresa están siempre dispuestos a suprimir todo movimiento arbitrario $^{56 "}$.

8. El poder fiscal del Estado, es una modalidad de relaciones especiales de sujeción de los ciudadanos, expresado en obligaciones, control y vigilancia, a cambio de las ventajas que el Estado brinda a los ciudadanos.

Durante la época de Weimar, cuya carta fundamental, es uno de los antecedentes directos del Estado Social y marcó el tránsito del Estado Liberal al Estado Social y de Derecho, en 1919; en ella se mantienen los elementos de la con-

54 LÓPEZ BENÍTEZ, Mariano. Naturaleza y presupuestos constitucionales de las relaciones especiales de sujeción. Universidad de Córdoba. Civitas. 1994, pág. 71.

55 LÓPEZ BENÍTEZ, Mariano. Naturaleza y presupuestos constitucionales de las relaciones especiales de sujeción. Universidad de Córdoba. Civitas. 1994, pág. 71.

56 LÓPEZ BENÍTEZ, Mariano. Naturaleza y presupuestos constitucionales de las relaciones especiales de sujeción. Universidad de Córdoba. Civitas. 1994, pp. 74-80. 
ceptualización de Otto Mayer anteriormente descritos para la categoría jurídica de las relaciones especiales de sujeción.

Esta Constitución elaborada en medio de grandes trastornos sociales y políticos, entre ellos los causados por la derrota de Alemania en la Primera Guerra Mundial, caracteriza un Estado democrático liberal. En ella se incorporó un amplísimo catálogo de derechos, y por primera vez, junto a la Constitución mexicana de 1917, se constitucionalizaron derechos sociales. Con esta construcción el Estado de Derecho alemán se consolidó en el siglo pasado como un Estado de Derecho limitado a la Administración. Los derechos fundamentales "se concebían principalmente como afirmaciones de la ley objetiva, que restringían el poder estatal, y no como derechos subjetivos de los ciudadanos.

El Artículo 114 de la constitución de Weimar, señala: "La libertad de la persona es inviolable. Todo menoscabo o supresión de la libertad personal por el poder público solo está permitido en base a una ley". Pero este principio de supremacía de la ley se refiere a las relaciones generales de sujeción y no a las especiales.

En este periodo las relaciones especiales de sujeción se ven, en decir de Forsthoff, citado por López Benitez, como una "laguna del Estado de Derecho" 57 . Los efectos pretendidos con el principio de legalidad así descrito, en relación con la intervención de la Administración en la esfera del individuo, no son de aplicación en las relaciones especiales de sujeción, por su imprevisibilidad y finalidad. Autores como Gallego Anabitarte Alfredo ${ }^{58}$, explican la inaplicabilidad de este naciente principio a las relaciones especiales de sujeción, así: "La creación de una

57 LÓPEZ BENÍTEZ, Mariano. Naturaleza y presupuestos constitucionales de las relaciones especiales de sujeción. Universidad de Córdoba. Civitas. 1994, pág. 79.

58 LÓPEZ BENÍTEZ, Mariano. Naturaleza y presupuestos constitucionales de las relaciones especiales de sujeción. Universidad de Córdoba. Civitas. 1994, pág. 120.
Institución supone la aceptación del fin que persigue y que deberá cumplir. Tras esto se establece la correspondiente regulación que garantizará la seguridad. El problema surge cuando esa regulación no es realizable: a) dada la imposibilidad de determinar la extensión y contenido de las respectivas prestaciones, así como la intensidad de las posibles intervenciones en la esfera de los afectados, es decir, cuando entra en juego la llamada imprevisibilidad; b) o, cuando en el caso de que dicha regulación fuese llevada a cabo, fuese la consecuencia de una considerable pérdida en eficiencia y productividad de la Administración. Y esto es, justamente, el caso en las relaciones especiales de sujeción; "no habría regulación normativa lo suficientemente detallada en el Derecho Militar, ni el Derecho regulador del orden de la enseñanza y de los establecimiento públicos, capaz de apurar todos los puntos de contacto disciplinarios"',"

El nacimiento del Estado de Derecho, no conlleva el condicionamiento al principio de legalidad de las relaciones especiales de sujeción; para entonces su concepto y alcance están condicionados y justificados en la operatividad y eficacia de la organización ${ }^{59}$; la constitucionalización de los derechos fundamentales no evita la mengua y sacrificio propios de los funcionarios en aras del servicio a cargo de la Administración. Con el advenimiento de Hitler y a pesar del papel determinante que juega el Ejército en esta época, su condición de principal protagonista de las relaciones especiales de sujeción, no contribuye al fortalecimiento conceptual o material de dicha categoría; por el contrario, se debilita no solo la teoría clásica de las relaciones de sujeción sino que se genera un retroceso en los avances descritos para las relaciones generales ${ }^{60}$.

59 GALLEGO ANABITARTE, Alfredo. Las Relaciones especiales de sujeción y el principio de la legalidad de la administración. En: "Revista del Administración Pública", no. 34, 1961, pp. 11-52. Recuperado de: http: //www.cepc.es/rap/Publicaciones/Revistas/1/ 1961_034_011; PDF, el 08 de junio de 2008.

60 GÓMEZ PAVAJEAU, Carlos Arturo. REYES CUARTAS, Jose Fernando. Estudios de Derecho Disciplinario. Ediciones Jurídicas Gustavo Ibañez. Ediciones Nueva Jurídica. 2004, pág. 21. 
Con la Ley fundamental de Bonn, surgió la república Federal de Alemania, el 23 de mayo de 1949, como un Estado social y de Derecho y con ella la consagración de una serie de instituciones y derechos que lo caracterizan.

Pero al igual que la Constitución de Weimar la Ley Fundamental de Bonn, no resolvió las dudas sobre la atadura de la Administración y de las relaciones especiales de sujeción, al principio de legalidad.

Desde el nacimiento del Estado social y de Derecho en la Ley Fundamental, se han generado tensiones entre una y otra caracterización; la libertad individual frente al poder estatal, la división de poderes, el principio de legalidad, la autonomía judicial, propios del Estado de Derecho, no siempre coexisten pacíficamente frente a la necesidad de intervención estatal para asegurar la garantía efectiva y material de los derechos fundamentales, propia del Estado Social.

El mandato de la Ley Fundamental de Bonn sobre la estricta vinculación de las relaciones generales de sujeción a la ley, en tanto cualquier intervención en los derechos individuales requiere de una base legal, no conserva tal rigurosidad para las relaciones especiales de sujeción. En cuanto, el Estado de Derecho es de raigambre constitucional, el Estado Social posee en la mayoría de los casos un origen administrativo. Las tensiones entre uno y otro, encuentran su solución en el marco de las relaciones especiales de sujeción; si bien es cierto muchas de ellas cuentan con una base legal formal, como las normas que establecen la enseñanza obligatoria o la sentencia que permite la libertad vigilada, también es cierto que para la Administración mantener la efectividad, requiere de un espectro de producción jurídica, que no es necesariamente una ley formal, sino disposiciones, reglamentos administrativos o actos administrati$\operatorname{vos}^{61}$. Aún así, todo acto del ejecutivo requiere

${ }^{61}$ LÓPEZ BENÍTEZ, Mariano. Naturaleza y presupuestos constitucionales de las relaciones especiales de sujeción. Universidad de Córdoba. Civitas. 1994, pág. 113. de una autorización legal y por lo tanto la ley fundamental es el marco jurídico de las relaciones especiales de sujeción.

Estas afirmaciones son válidas y deducibles de la Ley Fundamental de Bonn, siempre y cuando se entienda la ley en el Estado de Derecho, desde la perspectiva de ley abstracta, general y formal, propia de un sistema parlamentario.

Esta proyección subsistió hasta la reunión de Mainz de profesores de Derecho Público, realizada en octubre de $1956^{62}$, en la que se presenta a las relaciones especiales de sujeción en una sociedad motivada en la Norma Fundamental de Bonn. Las ponencias de Herbert Krüger ("E1 Poder y el Derecho en las relaciones especiales de sujeción") y Carl Hermann Ule, ("La distinción entre relación fundamental y relación de empresa"), condujeron a reconocer: (I) que la reserva de ley afecta las relaciones especiales de sujeción, en tanto no hay espacios ajurídicos en donde la Administración encuentre un terreno propio y autónomo; (II) que las relaciones de los ciudadanos con el Estado no son solo de sujeción o de poder, son tantas como las necesidades del ciudadano en torno al Estado; (III) que las relaciones especiales de sujeción, permiten ejercer los derechos fundamentales, en el límite de los objetivos de la institución; (IV) que estos objetivos originan una "relación fundamental", sometida a control judicial, y en este sentido una relación jurídica; (V) que las relaciones meramente "funcionales" u "organizativas" o "de empresa", quedan excluidas de la protección o control judicial ${ }^{63}$.

62 LÓPEZ BENÍTEZ, Mariano. Naturaleza y presupuestos constitucionales de las relaciones especiales de sujeción. Universidad de Córdoba. Civitas. 1994, pp. 123 y siguientes.

63 COTINO, Lorenzo. Relaciones de especial sujeción: su diversa evolución en Alemania y España. (particular seguimiento de la jurisprudencia constitucional, contencioso-administrativa y militar de la presente década). En: "Revista del Poder Judicial", (3 ${ }^{a}$. Época), no. 55, 1999 (III), pp. 291-324. Recuperado de: http: //www.cotino. net/Publicaciones/, el 08 de junio de 2008. 
El siguiente paso en la evolución germana de esta categoría se refleja en la sentencia del Tribunal Constitucional Federal, de 14 de marzo de 1972, que reconoce la existencia de las relaciones especiales de sujeción "como límites implícitos de los derechos fundamentales de los presos", siendo inconstitucional o inviable el que no se respeten las garantías formales (reserva de ley) establecidas en beneficio y garantía de los derechos fundamentales ${ }^{64}$. Esta jurisprudencia se extendió a las relaciones en los cuarteles, en los centros docentes y con los funcionarios y las dotó de mayor protección jurisdiccional frente a las medidas internas de la Administración ${ }^{65}$.

A partir de entonces, la subsistencia de esta categoría jurídica esta condicionada a la necesidad de acudir al tenor de la Norma Superior tanto en relación con la finalidad de la institución como de los requisitos de admisibilidad y viabilidad de la imposición de limites a los derechos fundamentales en favor del buen funcionamiento de la Administración.

En este análisis sobre el nacimiento de las relaciones especiales de sujeción como categoría jurídica, no puede olvidarse el papel determinante que jugó la revolución Francesa en el surgimiento de la Administración Pública moderna. Los principios de legalidad y de democracia representativa, reforzaron el carácter del funcionario público como agente del Estado e instrumento de la ley. El modelo francés cuenta con una Administración fuertemente centralizada que ejerce funciones de autoridad con un sistema de funcionarios públicos cerrado o de carrera. Sin embargo, el funcionario público no es un trabajador cualquiera, cuyas condiciones de vinculación son determinadas en forma unilateral por la administración, es decir, es una relación estatutaria, o relación de sujeción especial, según la doctrina alemana.

64 LÓPEZ BENITEZ, Mariano. Naturaleza y presupuestos constitucionales de las relaciones especiales de sujeción. Civitas, Madrid, 1994, pp. 122-135.

65 LÓPEZ BENITEZ, Mariano. Naturaleza y presupuestos constitucionales de las relaciones especiales de sujeción. Civitas, Madrid, 1994, pp. 146-148.
Las potestades del ejecutivo eran solo las necesarias para ejecutar la ley; siempre dependían de las decisiones de la Asamblea Nacional. Poseía potestad de mando y disciplina; de reglamentación para ejecutar la ley; de ejecutividad para aplicarla a casos concretos a través de actos administrativos. Excepcionalmente podía adoptar actos políticos, que no eran objeto ni de control político ni jurisdiccional. Todo el ordenamiento jurídico estaba cubierto por la ley, "... lo que implica que todos los ciudadanos estaban vinculados a una relación de sujeción general sin derivación de espacios autónomos a favor de la rama ejecutiva ${ }^{66 "}$.

A partir de entonces, la tarea del Estado no consistía en proteger libertades públicas, sino en obrar positivamente en la sociedad para otorgar a los ciudadanos una serie de servicios efectivos que les permitieran mejorar sus condiciones de existencia. De la teoría del Estado gendarme se pasa al Estado-servidor, situación que provocó una nueva manera de relacionarse con los ciudadanos-administrados y con los ciudadanos-servidores públicos. Por lo anterior, debemos colegir que en Francia predominaba un principio de sujeción general de los ciudadanos frente al Estado, basado primordialmente en el principio de igualdad ante la ley.

Es decir, el orden político perdió su base trascendente radical para reducirse a un mundo propio de los hombres en que se aplica. El poder se apoya en la propia voluntad general de la comunidad, no en una instancia extra o supracomunitaria. Los individuos, pasan a ser dueños del poder, no su objeto como hasta ahora; dejan de ser súbditos para convertirse en ciudadanos ${ }^{67}$.

66 COTINO, Lorenzo. Relaciones de especial sujeción: su diversa evolución en Alemania y España (particular seguimiento de la jurisprudencia constitucional, contencioso-administrativa y militar de la presente década). En: "Revista del Poder Judicial", (3 ${ }^{\mathrm{a}}$. Época), no. 55, 1999 (III), pp. 291-324. Recuperado de: http: //www. cotino. net/Publicaciones/, el 08 de junio de 2008.

67 GÓMEZ PAVAJEAU, Carlos Arturo. MOLANO LÓPEZ, Carlos Arturo. La relación especial de sujeción. Estudios. Universidad Externado de Colombia. 2007, pág. 36. 
El ciudadano en su calidad de sujeto activo frente a la Administración, puede estar en dos posiciones: como administrado simple o como administrado cualificado. En la primera ostenta una posición genérica y simple, "relación general de poder" o "relación de supremacía general o "relación general de sujeción". "La Administración se presenta en estas relaciones armada con sus potestades generales, las que la Ley le atribuye por su condición genérica de tal (reglamentaria, impositiva, expiatoria, policial, sancionatoria, etc.)...", señala García de Enterría en la obra en referencia. ${ }^{68}$

En la segunda posición "...el administrado cualificado matiza su posición de un status especial que le singulariza de la situación genérica por virtud de un tipo de relación concreta que le liga con la administración de una manera específica ${ }^{69}$ ", continúa García de Enterría en la obra en referencia. En esta posición el administrado ingresa a la organización administrativa y se somete a una situación de dependencia con la misma, entablándose entre los dos una "relación especial de poder" o "de sujeción especial". El administrado se somete a las condiciones del establecimiento, que no son otras que su propia "disciplina "; en estas condiciones el sometimiento del ciudadano, podría llevar a la restricción de algunos de sus derechos fundamentales; es el caso del soldado, del funcionario público ${ }^{70}$.

\section{CONCLUSIONES}

Gran parte de la doctrina considera que Otto Mayer es el artífice de la teoría de la categoría jurídica de las relaciones especiales de sujeción en el Derecho Administrativo y en especial en el marco del Estado constitucional.

68 GARCÍA DE ENTERRÍA, Eduardo. Curso de Derecho Administrativo, Edit Civitas, Madrid. Reimpresión 2001. Tomo II, pág. 18

69 GARCÍA DE ENTERRÍA, Eduardo.Curso de Derecho Administrativo, Edit Civitas, Madrid. Reimpresión 2001. Tomo II, pág. 20.

70 GARCÍA DE ENTERRÍA, Eduardo. Curso de Derecho Administrativo, Edit Civitas, Madrid. Reimpresión 2001. Tomo II, pág. 19.
En su construcción como categoría jurídica se mezclaron los criterios de libertad y legalidad del constitucionalismo francés, con los matices autoritarios del naciente constitucionalismo alemán.

Las relaciones especiales de sujeción reflejan en su nacimiento potestades del ejecutivo no sometidas a derecho; estas potestades regulan las relaciones de servicio entre la Administración y los funcionarios mediante reglas de conducta y deberes de obediencia.

La cláusula general de vigencia del Estado de Derecho, trae como consecuencia necesaria el sometimiento de la Administración y de las relaciones especiales de sujeción al principio de legalidad.

\section{BIBLIOGRAFÍA}

BRAGE CAMAZANO, Joaquín. Los límites a los derechos fundamentales, Madrid, Dykinson, 2004.

Corte Constitucional. Sentencia 417 de 1993: Magistrado ponente Fabio Morón Díaz.

COTINO, Lorenzo. Relaciones de especial sujeción: su diversa evolución en Alemania y España. (particular seguimiento de la jurisprudencia constitucional, contencioso-administrativa y militar de la presente década). En: "Revista del Poder Judicial”, (3 $3^{\text {a }}$ Época), no. 55, 1999 (III), pp. 291324. Recuperado de : http: //www.cotino. net/ Publicaciones/, el 08 de junio de 2008

GARCIA DE ENTERRIA, Eduardo. Curso de Derecho Administrativo, Edit Civitas, Madrid. Reimpresión 2001. Tomo II.

GARCIA Macho, Ricardo. Las Relaciones de Especial Sujeción en la Constitución Española. Edt. Tecnos, Madrid, 1992.

GALLEGO ANABITARTE, Alfredo. Las relaciones especiales de sujeción y el principio de la legalidad de la administración. Contribución a la teoría del 
Estado de derecho. En: "Revista de Administración Pública". ISSN 0034-7639, No. 34-1961, pp. 11-52. Recuperado de: http: //www.cepc. es/rap/Publicaciones/Revistas/1/1961_034_ 011.PDF, el 08 de junio de 2008.

HUBERMAN Leo, Los bienes terrenales del hombre. Editorial Oveja Negra. Abril de 1972

LASAGABASTER Herrarte, Iñaki. Las Relaciones de Sujeción Especial, Edit Civitas, Madrid 1994.

MOLANO López, Mario Roberto. Las Relaciones de Sujeción Especial en el Estado Social. Instituto de Estudios del Ministerio Público, Bogotá, 2005.
PAVAJEAU Gómez, Carlos Arturo. Dogmática del Derecho Disciplinario. Universidad Externado de Colombia. Bogotá. 2002.

PAVAJEAU Gómez Carlos Arturo. MOLANO López Mario Roberto, La relación especial de sujeción. Estudios. Universidad Externado de Colombia. 2007.

PENAGOS Gustavo. Fundamentos del Derechos Administrativo. Ediciones Librería del Profesional. Primera edición 1993.

SANTOFIMIO, José Orlando. Tratado de Derecho Administrativo. Tomo I. Universidad Externado de Colombia. Bogotá. 2002.

LOPEZ Benítez Mariano, Naturaleza y presupuestos constitucionales de las relaciones especiales de sujeción. Universidad de Córdoba. Civitas. 1994. 